\title{
A Review on Bone Mineral Density Loss in Total Knee Replacements Leading to Increased Fracture Risk
}

\author{
M. Gundry ${ }^{1}$ - S. Hopkins ${ }^{1}$ - K. Knapp ${ }^{1}$
}

Published online: 27 October 2017

(C) The Author(s) 2017. This article is an open access publication

\begin{abstract}
The link between low bone mineral density (BMD) scores leading to greater fracture risk is well established in the literature; what is not fully understood is the impact of total knee replacements/revisions or arthroplasties on BMD levels. This literature review attempts to answer this question. Several different databases using specific key terms were searched, with additional papers retrieved via bibliographic review. Based on the available evidence, total knee replacements/revisions and arthroplasties lower BMD and thus increase fracture risk. This review also addresses the possible implications of this research and possible options to reduce this risk.
\end{abstract}

Keywords Total knee replacement · TKR · Fracture risk · Bone mineral density $\cdot$ BMD

\section{Introduction}

Two of the predominant pathological disorders that affect bone mineral density (BMD) are osteoarthritis (OA) and osteoporosis $(\mathrm{OP})$. Due to the destructive nature of $\mathrm{OA}$ on the joints and the resulting loss of mobility and function, surgery

M. Gundry

Mg361@exeter.ac.uk

S. Hopkins

S.J.Hopkins@exeter.ac.uk

K. Knapp

K.M.Knapp@exeter.ac.uk

1 University of Exeter Medical School, St Luke's Campus, Heavitree Road, Exeter EX1 2LU, UK is a primary option, and as such, OA accounts for between 80 and $90 \%$ of all total knee replacement (TKR/arthroplasty) procedures [1-5].

The relationship between OA and OP is complex and has been reported to be an inverse one [6], with OA being reported to increase BMD, and thus, it might be assumed to increase fracture protection. With such a high percentage of cases of TKR due to OA, it could be concluded that this protective effect would reduce fracture risk in TKR patients due to having higher BMD, but increased fracture rates have also been reported in OA. A narrative literature review was conducted to investigate the links between $\mathrm{BMD}, \mathrm{OA}$, and fracture risk in TKR; these specific key terms were searched in different combinations across the databases: PubMed, Google Scholar, Web of Science and Embase, with additional papers retrieved via bibliographic review.

\section{The Relationship Between BMD and OA}

Research on the relationship between OA, BMD and the subsequent fracture risk has produced many controversial and conflicting results.

In 1972, Foss et al. were the first to observe the correlation between OA and fracture risk, concluding that patients with OA had a greater BMD for their age and thus had fewer hip fractures [6]. This suggested the possibility of a protective effect of OA due to higher BMD, with several studies supporting the link between OA and higher BMD (as shown in Table 1); Dequeker et al. in 2003 reviewed the relationship between increased severity of OA resulting in higher BMD scores, discovering 36 previous studies across 16 countries (Europe, the USA and Australia) covering a total of 37,774 subjects including 11,137 OA cases. Twenty-eight of these 


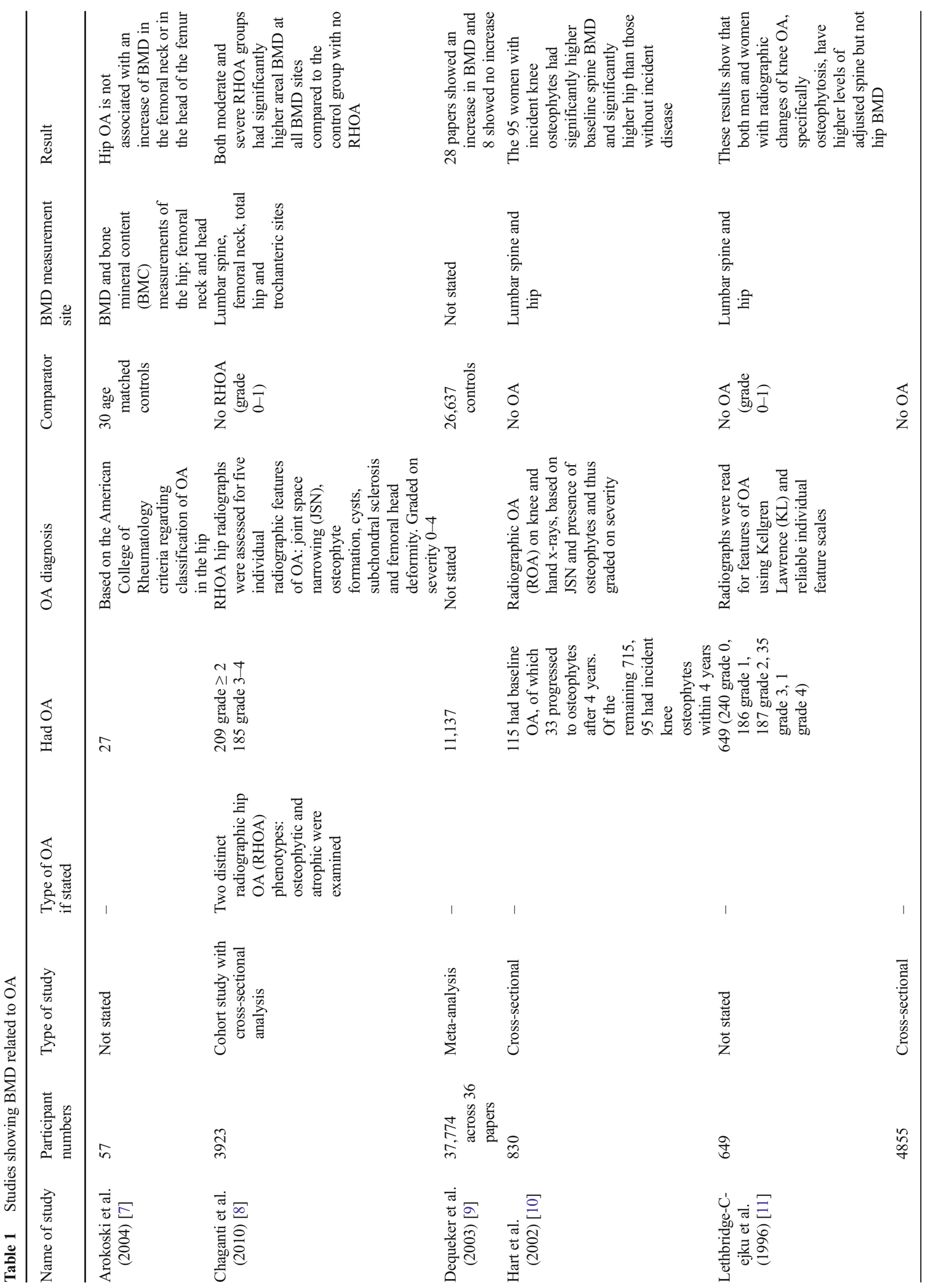


studies showed an increase in BMD with the remaining eight studies showing there was no increase in BMD [9].

A study by Hart et al. [10] showed 95 women had a higher hip and spine BMD versus controls $\left(0.79\right.$ versus $0.76 \mathrm{~g} / \mathrm{cm}^{2}$, or $3.9 \%$, and 1.01 versus $0.95 \mathrm{~g} / \mathrm{cm}^{2}$, or $6.3 \%$, for the hip and spine respectively); this itself is supported by other research [12] that concluded that OA resulted in higher BMD in the hip and spine, than women without hip OA. This trend was also seen in elderly men, who showed higher BMD in both the lumbar spine and hip compared to age-similar matched controls without OA [8]. This is further validated by research that shows an increase in BMD of the spine of patients with OA compared to controls $[11,13,14]$.

There is research that states that although spine BMD might be high, hip BMD was not, as investigated by Lethbridge-Cejku et al. [11] who recruited 402 men and 247 women with $\mathrm{OA}$. The results showed high levels of spine BMD but not hip BMD; this is supported by Arokoski et al. [7] whose findings suggest that hip OA is not associated with an increase of BMD in the femoral neck or in the head of the femur. It must be stated that there is also a small amount of research contrary to this that states OA lowers BMD compared to controls [15].

The majority of the research shows an increase in BMD in OA patients $[6,10-14,16]$, but it must be acknowledged that there are other factors in $\mathrm{OA}$; the phenotypes within OA such as osteophytic (which is osteophyte predominant [8]) and atrophic (which is joint space narrowing (JSN) predominant) both influence BMD scores. Out of the papers mentioned, only the Chaganti et al. study directly referred to the phenotypes' impact; they showed significant differences in the hip and lumbar spine of areal BMD (aBMD) measurements for the two radiographic hip OA (RHOA) phenotypes compared to the control group. The osteophytic RHOA group had a higher aBMD at all sites compared to the control group: $+3.9 \%$ at the total hip $(p=0.002),+8.5 \%$ at the femoral neck $(p<0.0001),+4.6 \%$ at the trochanter site $(p=0.002)$ and $+7.2 \%$ at the lumbar spine $(p=0.0003)$. In contrast, the atrophic phenotype was not significantly associated with any difference in aBMD compared to controls [8]. The other studies mainly graded $\mathrm{OA}$ on a combination of factors resulting in a severity score; as such, these results might not be universal and may be more likely associated with the osteophytic phenotype. This is further supported by research that showed that obese patients have a more osteophyte dominant OA pattern compared to non-obese patients, $74.5 \%$ compared to $34.8 \%$ [17]; this coupled with increasing obesity in the population and the association of obesity with the onset and progression of OA in the knee [18] resulting in more TKRs might reflect the associated BMD changed and OA diagnosis.

Due to this recorded increase in BMD, it is generally thought that this would translate to having a protective effect on the bone by reducing fracture risk. This does not seem to 
be the case as several studies have argued against the protective nature of $\mathrm{OA}$ and actually demonstrate an increase in fracture risk (as shown in Table 2). Reasons for this contradiction in correlation could be due to limitations in the DXA scans only measuring two dimensions and not accounting for bone depth [25]. Furthermore, research has demonstrated that osteophytes contribute between 16.6 and $22 \%$ of the lumbar spine BMD variation in DXA scans in women and men respectively [26], possibly leading to an overestimation of higher BMD without the increase in bone strength; this might also explain the osteophyte phenotype predominance BMD results shown by Chaganti et al.

This bone strength argument is further supported by Lee et al. [24] whose cross-sectional study proposed that despite OA subjects having high systematic BMD, they were positively associated with vertebral fractures. Lee et al. suggested that bone quality, and consequently bone strength, may be decreased at the systemic level in knee OA, resulting in a higher risk of fracture [24]. A similar idea is shared by Ding et al. [27] whose research looked at OA in post-mortem participants, using microcomputed tomography scans of the microarchitecture of the proximal tibiae. This showed that medial OA trabecular bone was significantly denser but had poorer mechanical properties than normal bone. Ding et al. suggested that bone remodelling in OA leads to deterioration in architecture, resulting in poor quality bone, so although BMD could be retained, the bone quality was less, resulting in the possibility of greater fracture risk. This effect might be explained due to subjects with OA having a greater proportion of undermineralisation (immature matrix) in the bone [28]. This rationale is further supported by some research suggesting that bone trabecular microarchitecture was the key determinant of fractures in addition to the BMD data [29].

It must be stated that bone quality is affected by many other factors, not only the influence of OA. This includes factors such as obesity (which results in an increased risk of OA [22, $30]$ ), diabetes and chronic kidney disease (CKD). Obesity is associated with higher BMD [31] but has been reported to lead to a lower rate of bone formation [32]. Type 2 diabetes is associated with higher BMD, but increased overall and hip fracture risk [33]. Research has shown that this might be due to changes in bone material properties rather than BMD, such as bone strength, structure, and quality, encompassing the microstructural and tissue material properties [34]. CKD can influence bone quality by altering bone turnover and mineralisation, resulting in microdamage and structural and material changes [35].

As shown in Table 2, several studies have argued against the protective nature of $\mathrm{OA}$, reporting an increase in fracture risk despite subjects having increased BMD. One study reported a BMD increase of 5.3\% compared to controls but no reduction in fracture risk [19]; this is further supported by the Rotterdam study [21] which utilised 2773 subjects and concluded that patients with knee OA had an increased risk of both vertebral (2.0-fold) and non-vertebral (1.5-fold) fractures. Furthermore, individuals with self-reported OA also had higher BMD but were not protected against non-vertebral osteoporotic fracture [23].

A study in 2014 [22] also demonstrated an increase in fracture rate among OA patients, in which 3864 subjects aged $>45$ years were analysed. Results revealed that fracture risk was significantly higher in women with OA than those without OA. A prospective randomised control trial conducted by Arden et al. supports this argument where over 6500 men and women $\geq 75$ years were recruited over 3 years, concluding that patients with knee pain and knee OA had an increased risk of non-vertebral and hip fracture [20].

It must be acknowledged that some studies have supported the idea of the OA protective effect; for example, Vestergaard et al. [36] conducted a case-control study using over 24,655 fractures matched for age and gender, with the main exposure being OA; their research showed that OA seemed to be associated with a decreased risk of fractures in multiple skeletal sites. This is agreed upon by Cumming and Klineberg [37] who had 189 participants (65-79 years old) with self-reported OA; the subjects with OA had fewer reported hip fractures than randomly assigned controls (4\% compared to $13 \%$ ). Additionally, Cumming et al. showed an inverse association between the number of joints reported to be affected by OA and the risk of hip fracture, with this protective effect being reported in both women and men [37].

Other research has shown a lack of any relationship between OA and fracture risk despite increased BMD [23, 38], with additional research using cohort studies showing no relationship between fracture risk and OA [39], contributing to the theory that $\mathrm{OA}$ does not have a protective effect on fracture risk.

Due to the contradiction and failure of the observed increase in BMD to translate into a protective effect and reduce fracture risk, several rationales were investigated. One rationale as to why an increased fracture risk may be explained, in part, was due to an increased fall tendency in patients with OA [38]. Research has shown that people with knee or hip OA have a greater number of falls and fracture risk compared to the general population [40, 41], even showing an increase in odds of falling correlated to the number of affected joints with OA [41].This theory is shared by other research [42], with some stating this is due to OA causing worsened postural stability and thus increasing the tendency to fall [23]. This is contradicted however by two cohort studies $[20,38]$ that reported that increased risk of fracture was independent of the number of falls. Although this in itself may be explained due to the severity of the falls and not the number of falls [20]. However, this rationale may be difficult to justify as fall data is often incomplete [43]. 


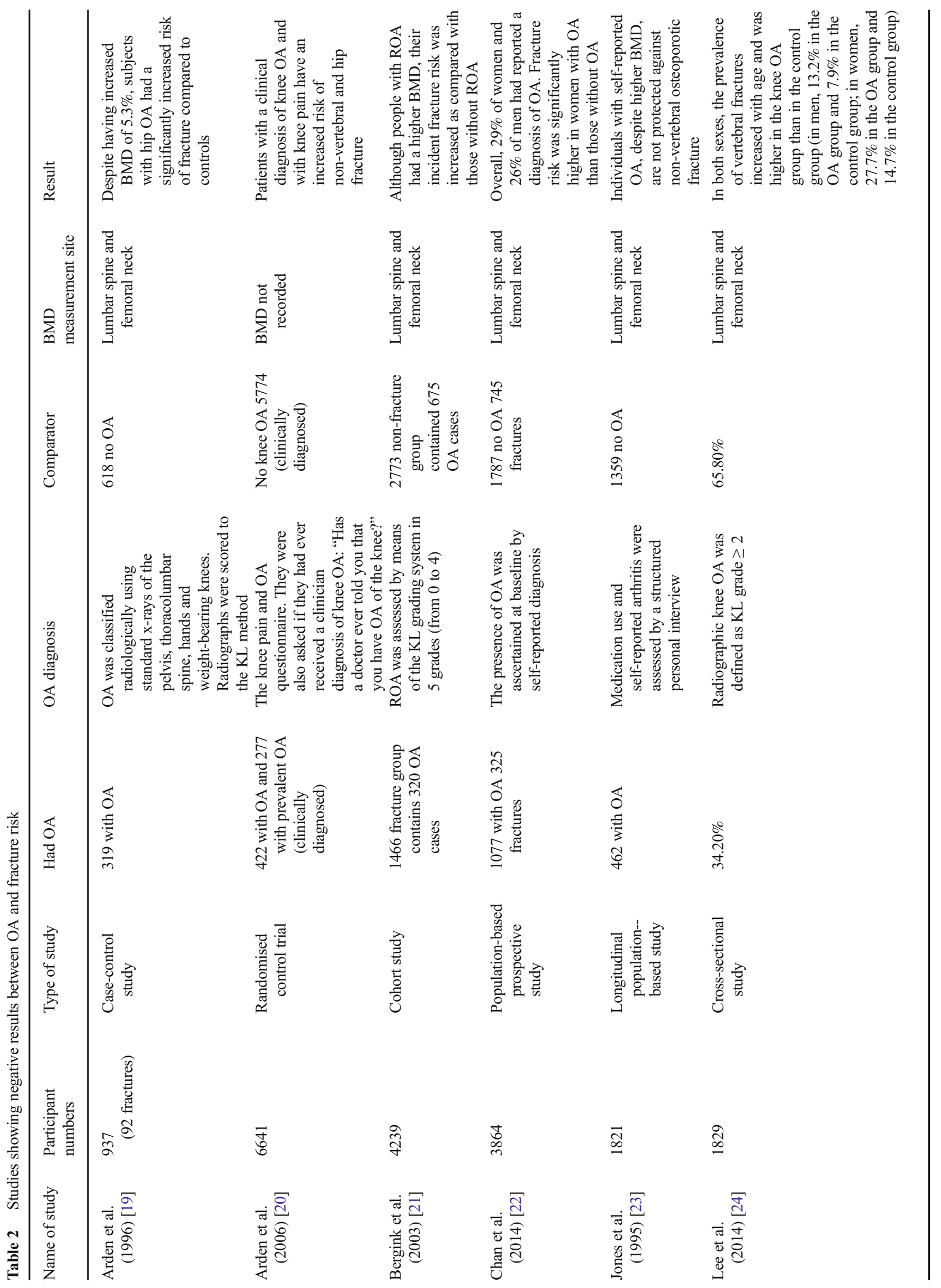


DXA bone density measurement provides an incomplete picture of bone strength as it is derived from the bone mineral content (BMC) divided by bone area, but does not account for the distribution of the trabeculae and the structural integrity of the microarchitecture. Bousson et al. created a tool called the trabecular bone score (TBS) [44] which is able to differentiate between microarchitectures that exhibit the same density [44]. This new method was investigated by Hopkins et al. [45] who recruited 19 post-menopausal women prior and post-TKR. The results exhibited that participants with TKR had higher mean lumbar BMD scores compared to controls but a lower TBS, suggesting that OA is potentially concealing poorer bone quality, even though it has a higher BMD. A further study by Hopkins et al. investigated differences in bone quantity and quality assessed by spine BMD and TBS [46]. These results demonstrated that the participants with TKR had higher BMD than the controls but poorer TBS scores [46].

TBS and BMD at the lumbar spine suggests that the generally higher BMD typically observed in OA patients may be disguising poor quality bone with less structural integrity [45]; this is supported by the rationale and results of the previous studies mentioned $[24,27]$ and might be the main reason that OA with high BMD does not a have protective effect in reducing fracture risk.

\section{BMD, Fracture and TKR Relationship}

The relationship between low BMD and increased fracture risk is well recognised [47-52], but the association between BMD scores, TKR and the associated fracture risk is not well established.

The majority of the research shows a loss of BMD after a TKR (arthroplasty) (Table 3); Gazdzik et al. [54] reported a decrease in BMD 12 months after TKR surgery with the most significant BMD decrease during the period of 512 weeks after the surgery at the periprosthetic region. Other research concurs with this, stating the greatest loss of periprosthetic BMD has been observed within the first 3 months (12 weeks) after surgery [61-63], with some research reporting a temporary BMD loss of $13 \%$ at the proximal tibia [57].

This BMD loss is further supported by a study by Kim et al. [56] who investigated 48 Korean patients (11 males, 37 females, mean age 63 years) post-TKR; they reported a significant decrease in BMD at the trochanters and femoral neck in the first 3 months post-surgery, followed by a recovery of the BMD losses to $-2.14 \%$ at 12 months. A similar trend is seen across the research by Ishii et al. [55], Hopkins et al. [45] and Petersen et al. [59] who all reported a decrease in total hip BMD during the first 6 months post-operatively.

Other research investigated the effects of TKR 12 months post-operatively. Beaupre et al. [53] conducted a cohort study across 12 months and demonstrated that BMD decreased significantly by $1.80 \%$ at the total hip over that time. Soininvaara et al. [60] measured the BMD of bilateral hips in 69 patients undergoing total knee arthroplasty (TKA) (20 males, 49 females, mean age 67 years). They found a decrease in BMD at 12 months post-operatively of up to $2.7 \%$ per year in the ipsilateral hip and up to $1.18 \%$ per year in the contralateral hip; this bone loss affecting the operated side more than the non-operated has been seen in other studies [58]. Mintzer et al. [64] reported that within the first 12 months post-operatively, $68 \%$ of patients had radiographic evidence of bone loss at the distal anterior femur. There are many more studies that have shown a correlation between TKR (arthroplasty) and BMD loss [59, 65-70], although there are some studies that dispute this association and have shown no change in BMD post-TKR/A [57, 71, 72], with some research actually showing a small increase [73].

It is argued that BMD recovers to a baseline by 2 years [74], with research showing the greatest loss is within the first 2 years and eventually stabilising at that point [75], although this in itself has been contested $[57,76]$. One explanation for this decline in BMD is a reduction in mobility of the patient post-surgery leading to reduced weight bearing and thus disuse related bone loss $[64,77]$; this potentially explains the trend of such significant BMD reductions in the first 6 months and levelling out at 2 years post-operatively [55].

Due to the majority of papers reporting a significant loss of BMD post-TKR/A, the possible associated fracture risk must be investigated (this is shown in Table 4). A study by Meek et al. reported that women aged $\geq 70$ years who had a TKR were 1.6 times more likely to have a fracture than younger patients and 2.3 times more likely to suffer a fracture than men [78]. This is further supported by Toogood et al. who stated that the greater majority of annual periprosthetic fractures were more often elderly and female [79]. Preliminary results from the Sahlgrenska Academy in Mölndal [80] analysed medical records from 1987 to 2002, concluding that individuals who had a TKR had an increased risk for hip fracture by $4 \%$, with the risk for vertebral fracture increasing by $19 \%$ compared to the population without TKR.

The Prieto-Alhambra et al. [43] research supports this increase in hip fracture after TKR reporting that hip fracture rates were insignificantly reduced compared to controls before the operation, but within 12 months post-operatively, TKR patients had a higher rate of hip fracture than controls, with relative risk increasing significantly up to 1.58 and then declining to equal the controls by 3 years. Additional research [42] has also shown a relationship between TKA and fracture risk, reporting a 54\% increased risk of hip fracture, in particular among adult patients aged 71 years old, with the increase risk of hip fracture greatest after the first few years. Other research has shown an even higher figure, reporting a 58\% increase in hip fracture in patients who had undergone TKR [43]. 


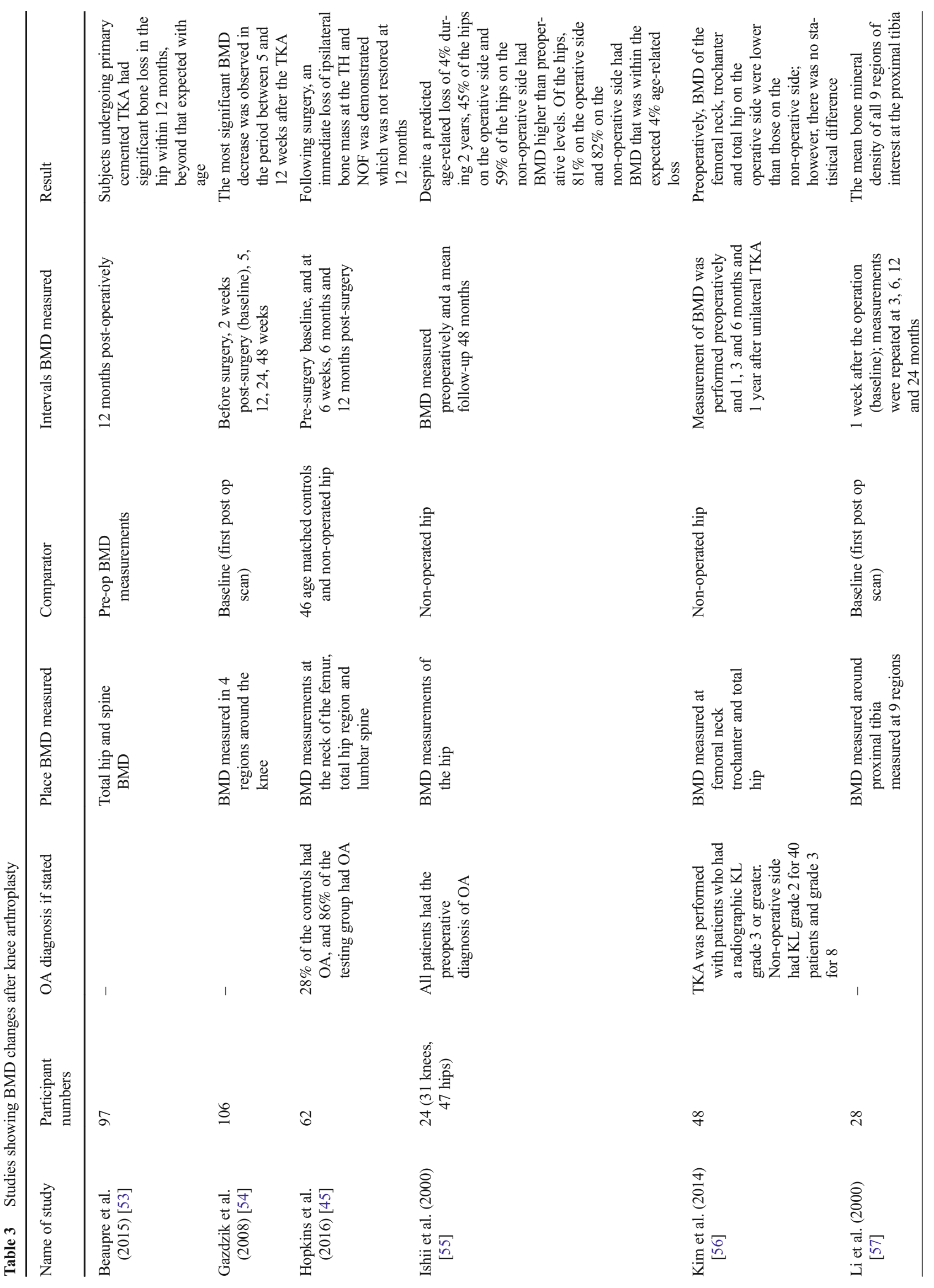




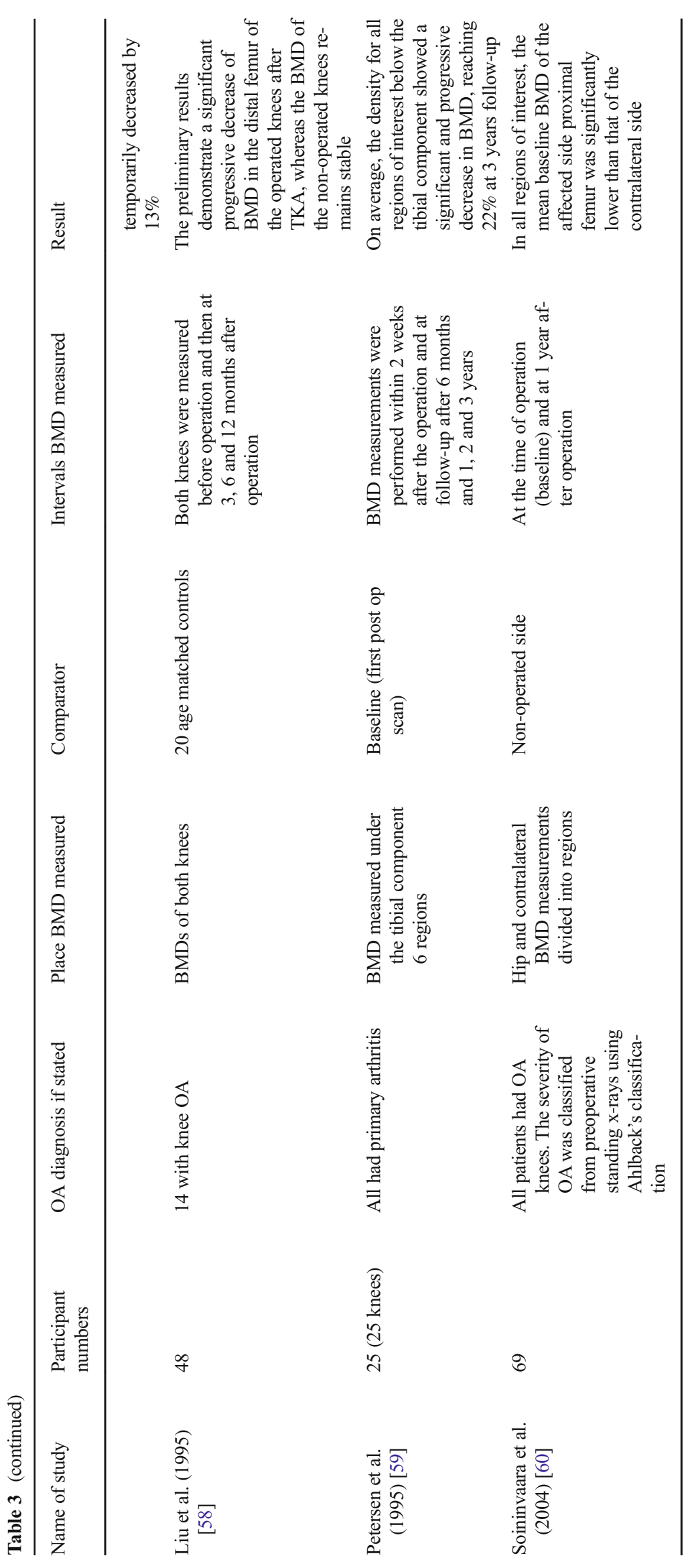


Table 4 Studies showing fracture risk with TKR

\begin{tabular}{|c|c|c|}
\hline Name of study & Participant numbers & Result \\
\hline Lalmohamed et al. (2012) [42] & $\begin{array}{l}6763 \text { cases ( } 89 \text { had knee arthroplasties (KA)), } \\
26,341 \text { controls ( } 208 \text { had a KA) }\end{array}$ & $\begin{array}{l}\text { A } 54 \% \text { increased hip fracture risk was found in patients } \\
\text { who underwent KA }\end{array}$ \\
\hline Meek et al. (2011) [78] & 44,511 primary TKRs and 3222 revision TKRs & $\begin{array}{l}\text { Comparison of survival analysis for all primary and } \\
\text { revision arthroplasties showed periprosthetic fractures } \\
\text { were more likely in females, patients aged }>70 \text { and } \\
\text { after revision arthroplasty }\end{array}$ \\
\hline Prieto-Alhambra et al. (2011) [43] & 20,033 knee OA (cases) 100,065 (controls) & $\begin{array}{l}\text { Hip fracture rates were non-significantly reduced compared } \\
\text { with controls before the operation. In the year after TKR, } \\
\text { risk increased significantly }\end{array}$ \\
\hline Toogood et al. (2015) [79] & $\begin{array}{l}\text { 30,624 (total joint arthroplasty, TKA and total } \\
\text { hip arthroplasty) }\end{array}$ & $\begin{array}{l}\text { Individuals admitted with periprosthetic fracture were older, } \\
\text { were more often female, were more often admitted emergently }\end{array}$ \\
\hline Vala et al. (2016) [80] & $\begin{array}{l}\text { The research followed the total Swedish } \\
\text { population born } 1902-1952(n=4,546,820) \\
\text { during the period } 1987-2002 \text { resulting in } \\
\text { a total of } 3719 \text { having TKR and a fracture }\end{array}$ & $\begin{array}{l}\text { After total knee replacement, the risk for hip fracture } \\
\text { increased by } 4 \% \text { and the risk for vertebral fracture } \\
\text { increased by } 19 \% \text { compared to the population without TKR }\end{array}$ \\
\hline
\end{tabular}

This increase in fracture risk during the first few years is time-dependent and as such could be associated with the evidence that supports early BMD decline as an important predisposing factor contributing to fracture risk [81-85].

There are other reasons put forward for the increased fracture risk in TKR patients, with some reports stating there is a higher incidence of falls thus a higher chance of fracture. Research by Matsumoto et al. [86] reported that of 81 patients who underwent TKA, the incidence of falls was $38 \%$ in the first year post-operatively, compared to $24 \%$ in the non-TKA cohort. Additional research also shows a higher rate of falls indicating scores of between 23 and 43\% [87-90]. Although some research contradicts this and shows fall incidences were not significantly higher in the TKR group [45].

One possible intervention is antiresorptive treatment. Hahn and Won [72] investigated this, concluding that bisphosphate treatment just after TKR surgery prevented early BMD reduction in the hip and would be beneficial in the prevention of later hip fracture. This is supported by research by Carulli et al. [91], who proposed the use of bisphosphonate treatment in patients to not only prevent bone loss but increase implant survival. Other studies [92] reviewed the effectiveness of bisphosphonate use on post-TKR fracture risk recruiting patients who had received a TKR between 1986 and 2006 for knee OA. They concluded that bisphosphonate treatment after a TKR reduced the risk of fracture by $50-55 \%$. Additionally, a meta-analysis [93] in 2015 reviewed the long-term effects in using bisphosphonates, reporting a significant decrease in implant revision after TKA or total hip arthroplasty (THA). Although caution should be utilised when administering bisphosphonates for long-term use, as research from 2017 has recently reported an increase in the size and number of microcracks leading to higher fracture risk in those patients on long-term bisphosphate use [94]. Furthermore, there have been reports of long-term use leading to increased atypical femoral fractures [95].

Some studies have looked at other possible antiresorptive treatments, such as hormone replacement therapy (HRT) to reduce BMD loss; several studies have shown an increase in BMD at all skeletal sites in early and late post-menopausal women [96, 97] with studies reporting a BMD increase of $5.3 \%$ at the lumbar spine and $7.6 \%$ at the femoral neck compared to 0.2 and $2.1 \%$, respectively, in the control placebo group [98], although it must be noted that long-term use of HRT is strongly associated with breast cancer [99], so longterm administration is no longer advisable [100].

Other possible antiresorptive treatments are selective oestrogen receptor modulators (SERM); these have been reported to show an increase in BMD in the femoral neck by $2.1-2.4 \%$ and in the spine by $2.6-2.7 \%$ compared to placebo controls [101]. Unfortunately, there are obstacles to SERM such as causing menopausal symptoms (breast pain, hot flushes) and resulting in an increase in thromboembolic events [102, 103].

In contrast to antiresorptive treatments, there are also anabolic agents; these stimulate bone growth, with currently the only approved anabolic for systemic use being parathyroid hormone (PTH) [104]; this treatment stimulates osteoblasts, thus promoting increased BMD, although PTH has been associated with side effects such as headaches, dizziness, joint pain, depression [105] and hypercalcemia [106]. Another anabolic treatment investigated was strontium ranelate [104]; this treatment is capable of encouraging bone growth via stimulating osteoblast activity [107]. This drug was withdrawn in 2017 [108] due to safety concerns such as cardiovascular risks and increase risk of death [109].

Other research has investigated the selection of materials, design and alignment of joint components for replacements and how these might impact BMD $[110,111]$. These mainly 
come in the form of metal implants and can be used in both tibial and femoral defects regardless of cementation.

These implants are primarily chosen due to being bioinert, able to support mechanical loads and being highly porous, promoting osteointegration [112]. Research has shown that tantalum cone implants were fully integrated after 2 years [113] and have been reported to maintain tibial bone density [114]; together with the material tantalum, porous titanium cones that mimic normal trabecular bone have been investigated; this type of implant has been shown to increase BMD at particular regions by $8.1 \%$ [115], with further research showing a similar favourable effect on BMD [116]. Some research however demonstrates that there is no significant difference in changes in BMD between the groups [117]. The titanium cone implants have also shown to have better stability than their tantalum counterparts [118]. In addition to the cones, some studies have investigated the effect of hydroxyapatite (a bioceramic that resembles the mineral constitutes of human bones and teeth [119]) coated onto the titanium implants to promote ingrowth; this combination has shown to increase shear strength [120] but has been reported to lead to decreased bone formation on porous coated titanium [121].

Metaphyseal sleeves have also been investigated; these come in a variety of different shapes and are press fitted into bone allowing bony ingrowth; research has reported excellent osteointegration and lasting fixation [122], showing ingrowth stability 3 months post-operation [123]. Unfortunately, there appears a lack of data about metaphyseal sleeves in TKR/A affecting BMD, with the main priority being stabilisation and survivorship.

\section{Conclusion}

Low BMD has long been associated with an increased fracture risk, and the majority of the research shows that TKR results in reduced BMD, with potential increased fracture risk for the first 2 to 3 years. As such, it is suggested that patients with low BMD should be treated in order to combat this either through antiresorptive therapies, anabolic treatments or particular specialised implants prior to surgery in order to reduce this risk. The influence of low BMD does not only affect the patient; $60 \%$ of orthopaedic surgeons have stated that low BMD would influence their surgical plan and the implant design, yet only $4 \%$ performed BMD measurements preoperatively [124]. This is suggested by other research and states that surgeons must consider BMD loss if they are relying on bone for long-term stable fixation of the prosthesis [70].

In cases of patients with reported OA, their BMD measurements should utilise an additional type of measurement in addition to the DXA scan, either TBS or other means of assessment in order to assess bone architecture. TBS itself has started to be recognised and has been used in osteoporosis diagnosis with further suggestion for it to be used as a tool to monitor treatment effects [125]. This assessment would all be in addition to clinical risk factors that contribute to fracture risk independently of BMD including age, previous fragility fracture, premature menopause, a family history of hip fracture and the use of oral corticosteroids [126].

Finally, it must be noted, for the associated risks of fracture with TKR/A, the impact on quality of life for the patient is paramount. Research has shown that those undergoing a TKR due to high risk of knee OA have an improved quality of life compared to those who do not get a TKR $[127,128]$. Furthermore, TKA has shown to have high patient satisfaction and long-term survival [129].

Funding This work will form part of the authors (Michael Gundry) $\mathrm{PhD}$ thesis in medical imaging which was part funded by the Stryker Institute with research investigating changes in BMD in bone surrounding cone implants on TKR revision patients.

\section{Compliance with Ethical Standards}

Disclosures Author Michael Gundry's current $\mathrm{PhD}$ is in part funded by the Stryker Institute with research investigating changes in BMD in bone surrounding cone implants on TKR revision patients. There is no grant number, but it is stated as an industry-funded, non-commercial study subject to a Masters Service Agreement between Stryker UK and the Royal Devon and Exeter Hospital. Additionally, authors Knapp and Hopkins have no conflict of interest to declare.

Ethical Approval This article does not contain any studies with human participants or animals performed by any of the authors.

Open Access This article is distributed under the terms of the Creative Commons Attribution 4.0 International License (http:// creativecommons.org/licenses/by/4.0/), which permits unrestricted use, distribution, and reproduction in any medium, provided you give appropriate credit to the original author(s) and the source, provide a link to the Creative Commons license, and indicate if changes were made.

\section{References}

1. Lohmander SL. Knee replacement for osteoarthritis; facts, hopes, and fears. Medicographia. 2013;35(2):181-8.

2. Koskinen EA, et al. Comparison of survival and cost-effectiveness between unicondylar arthroplasty and total knee arthroplasty in patients with primary osteoarthritis: a follow-up study of 50, 493 knee replacements from the Finnish Arthroplasty Register. Acta Orthop. 2008;79(4):499-507.

3. Knutson K, Lewold S, et al. The Swedish knee arthroplasty register. A nation-wide study of 30,003 knees 1976-1992. Acta Orthop Scand. 1994;65(4):375-86.

4. Hawker G, Wright J, et al. Health-related quality of life after knee replacement. J Bone Joint Surg Am. 1998;80(2):163-73.

5. National Institute for Health and Care Excellence. Osteoarthritis: care and management in adults clinical guideline [CG177]. 2014. https://www.nice.org.uk/Guidance/CG177. Accessed 24 March 2017.

6. Foss MVL, Byers PD. Bone density, osteoarthritis of the hip, and fracture of the upper end of the femur. Ann Rheum Dis. 1972;31: 259-64. 
7. Arokoski JPA, Arokoski MH, et al. Estimation of femoral head bone density using magnetic resonance imaging: comparison between men with and without hip osteoarthritis. J Clin Densitom. 2004;7(2):183-91.

8. Chaganti RK, Parimi N, et al. Bone mineral density and prevalent osteoarthritis of the hip in older men for the Osteoporotic Fractures in Men (MrOS) Study Group. Osteoporos Int. 2010;21(8):1307-16.

9. Dequeker J, Aerssens J, et al. Osteoarthritis and osteoporosis: clinical and research evidence of inverse relationship. Aging Clin Exp Res. 2003;15(5):426-39.

10. Hart CC, et al. The relationship of bone density and fracture to incident and progressive radiographic osteoarthritis of the knee: the Chingford study. Arthritis Rheum. 2002;46(1):92-9.

11. Lethbridge-Cejku M, Tobin JD, et al. Axial and hip bone mineral density and radiographic changes of osteoarthritis of the knee: data from the Baltimore Longitudinal Study of Aging. J Rheumatol. 1996;23(11):1943-7.

12. Nevitt MC, Lane NE, et al. Radiographic osteoarthritis of the hip and bone mineral density. The Study of Osteoporotic Fractures Research Group. Arthritis Rheum. 1995;38(7):907-16.

13. Hochberg MC, Lethbridge-Cejku M, et al. Bone mineral density and osteoarthritis: data from the Baltimore Longitudinal Study of Aging. Osteoarthr Cartil. 2004;12:45-8.

14. El Miedany YM, Mehanna AN, et al. Altered bone mineral metabolism in patients with osteoarthritis. Joint Bone Spine. 2000;67(6):521-7.

15. Perry ME, et al. Relationships between self-reported osteoarthritis (OA), bone mineral density (BMD) and radiographic scores using dual energy X-ray absorptiometry (DXA). Scott Med J. 2015;60(3):25-33

16. Hannan MT, Andersin JJ, et al. Bone mineral density and knee osteoarthritis in elderly men and women. The Framingham Study. Arthritis Rheum. 1993;36(12):1671-80.

17. Demirağ MD, Özkan S, et al. Associations between obesity and the radiographic phenotype in knee osteoarthritis. Turk J Med Sci. 2017;47(2):424-9.

18. Crowninshield RD, Rosenberg AG, et al. Changing demographics of patients with total joint replacement. Clin Orthop Relat Res. 2006;443:266-72.

19. Arden NK, Griffiths GO, et al. The association between osteoarthritis and osteoporotic fracture: the Chingford Study. Br J Rheumatol. 1996;35:1299-304.

20. Arden NK, Crozier S, et al. Knee pain, knee osteoarthritis, and the risk of fracture. Arthritis Rheum. 2006;55(4):610-5.

21. Bergink AP, Van Der Klift M, et al. Osteoarthritis of the knee is associated with vertebral and nonvertebral fractures in the elderly: the Rotterdam Study. Arthritis Care Res. 2003;49:648-57.

22. Chan MY, Center JR, et al. Bone mineral density and association of osteoarthritis with fracture risk. Osteoarthr Cartil. 2014;22(9): $1251-8$.

23. Jones G, Nguyen T, et al. Osteoarthritis, bone density, postural stability, and osteoporotic fractures: a population based study. J Rheumatol. 1995;22(5):921-5.

24. Lee S, Kim TN, et al. Knee osteoarthritis is associated with increased prevalence of vertebral fractures despite high systemic bone mineral density: a cross-sectional study in an Asian population. Mod Rheumatol. 2014;24(1):174-81.

25. Birch C, Hunter D, et al. Development of a novel imaging process to determine the clinical applicability of bone mineral density assessment of the osteoarthritic knee: a research proposal. Work Pap Health Sci. 2014;1(9):1-7.

26. Liu G, Peacock M, et al. Effect of osteoarthritis in the lumbar spine and hip on bone mineral density and diagnosis of osteoporosis in elderly men and women. Osteoporos Int. 1997;7(6):564-9.
27. Ding M, Odgaard A, et al. Changes in the three-dimensional microstructure of human tibial cancellous bone in early osteoarthritis. J Bone Joint Surg Br Vol. 2003;85(6):906-12.

28. Mansell JP, Bailey AJ. Abnormal cancellous bone collagen metabolism in osteoarthritis. J Clin Investig. 1998;101(8):1596-603.

29. Legrand E, Chappard D, et al. Trabecular bone microarchitecture, bone mineral density, and vertebral fractures in male osteoporosis. J Bone Miner Res. 2000;15(1):13-9.

30. Manninen P, Riihimäki $\mathrm{H}$, et al. Overweigh gender and knee osteoarthritis. Int J Obes. 1996;20(6):595-7.

31. Yang S, Shen X. Association and relative importance of multiple obesity measures with bone mineral density: the national health and nutrition examination survey 2005-2006. Arch Osteoporos. 2015;10:14.

32. Papakitsou EF, Margioris AN, et al. Body mass index (BMI) and parameters of bone formation and resorption in postmenopausal women. Maturitas. 2004;47(3):185-93.

33. Walsh JS, Vilaca T. Obesity, type 2 diabetes and bone in adults. Calcif Tissue Int. 2017;100(5):528-35.

34. Saito M, Kida Y, et al. Diabetes, collagen and bone quality. Curr Osteoporos Rep. 2014;12(2):181-8.

35. McNerny EMB, Nikolas TL. Bone quality in chronic kidney disease: definitions and diagnostics. Curr Osteoporos Rep. 2017;15(3):207-13.

36. Vestergaard P, Rejnmark L, et al. Osteoarthritis and risk of fractures. Calcif Tissue Int. 2009;84(4):249-56.

37. Cumming RG, Klineberg RJ. Epidemiological study of the relation between arthritis of the hip and hip fractures. Ann Rheum Dis. 1993;52:707-10.

38. Arden NK, Nevitt MC, et al. Osteoarthritis and risk of falls, rates of bone loss, and osteoporotic fractures. Arthritis Rheum. 1999;42(7):1378-85.

39. Jones G, Nquyen T, et al. A longitudinal study of the effect of spinal degenerative disease on bone density in the elderly. $\mathrm{J}$ Rheumatol. 1995;22(5):932-6.

40. Vennu V, Bindawas SM. Relationship between falls, knee osteoarthritis, and health-related quality of life: data from the Osteoarthritis Initiative study. J Clin Interv Aging. 2014;9:793-800.

41. Doré AL, Golightly YM, et al. Lower-extremity osteoarthritis and the risk of falls in a community-based longitudinal study of adults with and without osteoarthritis. Arthritis Care Res. 2015;67(5):633-9.

42. Lalmohamed A, Opdam F, et al. Knee arthroplasty and risk of hip fracture: a population-based, case-control study. Calcif Tissue Int. 2012;90(2):144-50.

43. Prieto-Alhambra D, Javaid MK, et al. Changes in hip fracture rate before and after total knee replacement due to osteoarthritis: a population-based cohort study. Ann Rheum Dis. 2011;70(1):134-8.

44. Bousson V, Bergot $\mathrm{C}$, et al. Trabecular bone score (TBS): available knowledge, clinical relevance, and future prospects. Osteoporos Int. 2012;23(5):1489-501.

45. Hopkins SJ, Toms AD, et al. A study investigating short- and medium-term effects on function, bone mineral density and lean tissue mass post-total knee replacement in a Caucasian female post-menopausal population: implications for hip fracture risk. Osteoporos Int. 2016;27(8):2567-76.

46. Hopkins SJ, Smith CW, et al. Relationship between spine bone mineral density and trabecular bone score in postmenopausal populations following total knee replacement or leg fracture. Osteoporos Int. 2012;23:S582.

47. Legrand E, Chappard D, et al. Bone mineral density and vertebral fractures in men. Osteoporos Int. 1999;10:265-70.

48. Marshall D, Johnell O, et al. Meta-analysis of how well measures of bone mineral density predict occurrence of osteoporotic fractures. Br Med J. 1996;312(7041):1254-9. 
49. De Laet CE, Van Hout BA, et al. Bone density and risk of hip fracture in men and women: cross sectional analysis. Br Med J. 1997;315(7102):221-5.

50. Cummings SR, Black DM, et al. Bone density at various sites for prediction of hip fractures. Lancet. 1993;341(8837):72-5.

51. Cummings SR, Nevitt MC, et al. Risk factor for hip fracture in white women. N Engl J Med. 1995;332(12):767-74.

52. Melton LJ 3rd, Wahner HW, et al. Osteoporosis and the risk of hip fracture. Am J Epidemiol. 1986;124(2):254-61.

53. Beaupre LA, Rezansoff A, et al. Bone mineral density changes in the hip and spine of men and women 1-year after primary cemented total knee arthroplasty: prospective cohort study. J Arthroplast. 2015;30(15):2185-9.

54. Gazdzik TS, Gajda T, et al. Bone mineral density changes after total knee arthroplasty: one-year follow-up. J Clin Densitom. 2008;11(3):345-50.

55. Ishii Y, Yagisawa K, et al. Changes in bone mineral density of the proximal femur after total knee arthroplasty. J Arthroplast. 2000;15(4):519-22.

56. Kim KK, Won YY, et al. Changes in bone mineral density of both proximal femurs after total knee arthroplasty. Clin Orthop Surg. 2014;6(1):43-8.

57. Li MG, Nilsson KG. Changes in bone mineral density at the proximal tibia after total knee arthroplasty: a 2-year follow-up of 28 knees using dual energy X-ray absorptiometry. J Orthop Res. 2000;18(1):40-7.

58. Liu TK, Yang RS, et al. Periprosthetic bone mineral density of the distal femur after total knee arthroplasty. Int Orthop. 1995;19(6): 346-51.

59. Petersen MM, Nielsen PT, et al. Changes in bone mineral density of the proximal tibia after uncemented total knee arthroplasty. A 3-year follow-up of 25 knees. Acta Orthop Scand. 1995;66(6):513-6.

60. Soininvaara TA, Miettinen HJ, et al. Bone mineral density in the proximal femur and contralateral knee after total knee arthroplasty. J Clin Densitom. 2004;7(4):424-31.

61. Soininvaara TA, Miettinen HJ, et al. Periprosthetic tibial bone mineral density changes after total knee arthroplasty: one-year follow-up study of 69 patients. Acta Orthop Scand. 2004;75(5):600-5.

62. Mau-Moeller A, Behrens M, et al. Modulation and predictors of periprosthetic bone mineral density following total knee arthroplasty. Biomed Res Int. 2015;2015:418168.

63. Järvenpää J, Soininvaara TA, et al. Changes in bone mineral density of the distal femur after total knee arthroplasty: a 7-year DEXA follow-up comparing results between obese and nonobese patients. Knee J. 2014;21(1):232-5.

64. Mintzer CM, Robertson DD, et al. Bone loss in the distal anterior femur after total knee arthroplasty. Clin Orthop Relat Res. 1990;260:135-43.

65. Jaroma A, Soininvaara TA, et al. Periprosthetic tibial bone mineral density changes after total knee arthroplasty a 7-year follow-up of 86 patients. Acta Orthop. 2016;87(3):268-73.

66. Lavernia CJ, Rodriguez JA, et al. Bone mineral density of the femur in autopsy retrieved total knee arthroplasties. J Arthroplast. 2014;29(8):1681-6.

67. Lonner JH, Klotz M, et al. Changes in bone density after cemented total knee arthroplasty: influence of stem design. J Arthroplast. 2001;16(1):107-11.

68. Im GI, Kwon OJ, et al. The relationship between osteoarthritis of the knee and bone mineral density of proximal femur: a crosssectional study from a Korean population in women. Clin Orthop Surg. 2014;6(4):420-5.

69. Karbowski A, Schwitalle M, et al. Periprosthetic bone remodelling after total knee arthroplasty: early assessment by dual energy Xray absorptiometry. Arch Orthop Trauma Surg. 1999;119(5-6): $324-6$.
70. Levitz CL, Lotke PA, et al. Long-term changes in bone mineral density following total knee replacement. Clin Orthop Relat Res. 1995;321:68-72.

71. Van Loon CJ, Oyen WJ, et al. Distal femoral bone mineral density after total knee arthroplasty: a comparison with general bone mineral density. Arch Orthop Trauma Surg. 2001;121(5):282-5.

72. Hahn MH, Won YY. Bone mineral density changes after total knee replacement in women over the age of 65 . J Bone Metab. 2013;20(2):105-9.

73. Petersen MM, Gehrchen PM, et al. Effect of hydroxyapatitecoated tibial components on changes in bone mineral density of the proximal tibia after uncemented total knee arthroplasty: a prospective randomized study using dual-energy x-ray absorptiometry. J Arthroplast. 2005;20(4):516-20.

74. Mann T, Eisler T, et al. Larger femoral periprosthetic bone mineral density decrease following total hip arthroplasty for femoral neck fracture than for osteoarthritis: a prospective, observational cohort study. J Orthop Res. 2015;33(4):504-12.

75. Cameron HU, Cameron G. Stress-relief osteoporosis of the anterior femoral condyles in total knee replacement: a study of 185 patients. Orthop Rev. 1987;16(7):449-56.

76. Van Lenthe GH, de Waal Malefijt MC, et al. Stress shielding after total knee replacement may cause bone resorption in the distal femur. J Bone Joint Surg Br Vol. 1997;79(1):117-22.

77. Hopkins SJ, Smith CW, et al. A study investigating the long-term effects on function, bone mineral density and lean tissue mass post total knee replacement in a female postmenopausal population. Osteoporos Int. 2012;23:S552.

78. Meek RM, Norwood T, et al. The risk of peri-prosthetic fracture after primary and revision total hip and knee replacement. Bone Joint J. 2011;93(1):96-101.

79. Toogood PA, Vail TP. Periprosthetic fractures: a common problem with a disproportionately high impact on healthcare resources. J Arthroplast. 2015;30(10):1688-91.

80. Vala $\mathrm{CH}$, Kärrholm J, et al. OC12 Risk for hip fracture ten years before and after total knee replacement surgery in the entire Swedish population. Abstract book: WCO-IOF-ESCEO World Congress on Osteoporosis, Osteoarthritis and Musculoskeletal Diseases, 14-17 April 2016, Malaga, Spain Osteoporosis International, 27(Supplement 1) 2016. http://2016.wco-iof-esceo. org/sites/all/files/wco16/WCO16-AbstractBook.pdf. Accessed 23 March 2017

81. Cordeiro EN, Costa RC, et al. Periprosthetic fractures in patients with total knee arthroplasties. Clin Orthop Relat Res. 1990;252: 182-9.

82. Dennis DA. Periprosthetic fractures following total knee arthroplasty. J Bone Joint Surg (Am Vol). 2001;83(1):120-30.

83. Merkel KD, Johnson EW Jr. Supracondylar fracture of the femur after total knee arthroplasty. J Bone Joint Surg (Am Vol). 1986;68(1):29-43.

84. Engh GA, Ammeen DJ, et al. Instructional course lectures, the american academy of orthopaedic surgeons - periprosthetic fractures adjacent to total knee implants. Treatment and clinical results. J Bone Joint Surg (Am Vol). 1997;79:1100-13.

85. Beals RK, Tower SS. Periprosthetic fractures of the femur. An analysis of 93 fractures. Clin Orthop Relat Res. 1996;327:238-46.

86. Matsumoto $\mathrm{H}$, Okuno $\mathrm{M}$, et al. Incidence and risk factors for falling in patients after total knee arthroplasty compared to healthy elderly individuals. Yonago Acta Medica. 2014;57(4):137-45.

87. Soison A, Riratanapong S, et al. Prevalence of fall in patients with total knee arthroplasty living in the community. J Med Assoc Thail. 2014;97(12):1338-43.

88. Ikutomo H, Nagai $\mathrm{K}$, et al. Falls in patients after total hip arthroplasty in Japan. J Orthop Sci. 2015;20(4):663-8.

89. Swinkels A, Allain TJ. Physical performance tests, self-reported outcomes, and accidental falls before and after total knee 
arthroplasty: an exploratory study. Physiother Theory Pract. 2013;29(6):432-42.

90. Swinkels A, Newman JH, et al. A prospective observational study of falling before and after knee replacement surgery. Age Ageing. 2009;38(2):175-81.

91. Carulli C, Civinini R, et al. The use of anti-osteoporosis drugs in total knee arthroplasty. Aging Clin Exp Res. 2011;23(2):38-9.

92. Prieto-Alhambra D, Javaid MK, et al. Bisphosphonate use and risk of post-operative fracture among patients undergoing a total knee replacement for knee osteoarthritis: a propensity score analysis. Osteoporos Int. 2011;22(5):1555-71.

93. Teng $\mathrm{S}$, Yi C, et al. Bisphosphonate use and risk of implant revision after total hip/knee arthroplasty: a meta-analysis of observational studies. Public Libr Sci. 2015;10(10):e0139927.

94. Ma S, Goh EL. Long-term effects of bisphosphonate therapy: perforations, microcracks and mechanical properties. Sci Rep. 2017;7:43399.

95. Kharwadkar N, Mayne B, et al. Bisphosphonates and atypical subtrochanteric fractures of the femur. Bone Joint Res. 2017;6(3):144-53.

96. Bjarnason NH, Hassager C, et al. Postmenopausal bone remodelling and hormone replacement. Clim J Int Menopause Soc. 1998;1(1):72-9.

97. Torgerson DJ, Bell-Syer SE. Hormone replacement therapy and prevention of nonvertebral fractures: a meta-analysis of randomized trials. J Am Med Assoc. 2001;285(22):2891-7.

98. Lufkin EG, Wahner HW, et al. Treatment of postmenopausal osteoporosis with transdermal estrogen. Ann Intern Med. 1992;117(1):1-9.

99. Beral V, Million Women Study Collaborators. Breast cancer and hormone-replacement therapy in the million women study. Lancet. 2003;362(9382):419-27.

100. Jordan N, Barry M, et al. Comparative effects of antiresorptive agents on bone mineral density and bone turnover in postmenopausal women. Clin Interv Aging. 2006;1(4):377-87.

101. Ettinger B, Black DM, et al. Reduction of vertebral fracture risk in postmenopausal women with osteoporosis treated with raloxifene: results from a 3-year randomized clinical trial. Multiple Outcomes of Raloxifene Evaluation (MORE) Investigators. J Am Med Assoc. 1999;282(7):637-45.

102. Romero A, Alonso C, et al. Risk of venous thromboembolic disease in women a qualitative systematic review. Eur J Obstet Gynecol Reprod Biol. 2005;121(1):8-17.

103. Cosman F, Baz-Hecht M, et al. Short-term effects of estrogen, tamoxifen and raloxifene on hemostasis: a randomizedcontrolled study and review of the literature. Thromb Res. 2005;116(1):1-13.

104. Arnett T. Basics of bone biology. Osteoporos Rev. 2015;23(2):12-6.

105. National Osteoporosis Society. Drug treatments for osteoporosis. 2016. https://nos.org.uk/media/1594/drug-treatments-forosteoporosis-parathyroid-hormone-treatment-january-2016.pdf. Accessed 23 March 2017.

106. Borba VZC, Manas NCP. The use of PTH in the treatment of osteoporosis. Arq Bras Endocrinol Metabol. 2010;54(2):213-9.

107. Almeida MM, Nani EP, et al. Strontium ranelate increases osteoblast activity. Tissue Cell. 2016;48(3):183-8.

108. National Osteoporosis Society. National osteoporosis update. Osteoporos Rev. 2017;25(1):14.

109. Abrahamsen B, Grove EL, et al. Nationwide registry-based analysis of cardiovascular risk factors and adverse outcomes in patients treated with strontium ranelate. Osteoporos Int. 2014;25(2):757-62.
110. Minoda Y, Ikebuchi M, et al. A cemented mobile-bearing total knee replacement prevents periprosthetic loss of bone mineral density around the femoral component: a matched cohort study. J Bone Joint Surg Br Vol. 2010;92(6):794-8.

111. Zhang QH, Cossey A, et al. Stress shielding in periprosthetic bone following a total knee replacement: effects of implant material, design and alignment. Med Eng Phys. 2016;38(12):1481-8.

112. Howard JL, Kudera LE, et al. Early results of the use of tantalum femoral cones for revision total knee arthroplasty. J Bone Joint Surg Am. 2011;93(5):478-84.

113. Lachiewicz B, Handerson RA, et al. Can tantalum cones provide fixation in complex revision knee arthroplasty? Clin Orthop Relat Res. 2012;470(1):199-204.

114. Harrison AK, Gioe TJ, et al. Do porous tantalum implants help preserve bone?: Evaluation of tibial bone density surrounding tantalum tibial implants in TKA. Clin Orthop Relat Res. 2010;468(10):2739-45.

115. Winther N, Jensen C, et al. Changes in bone mineral density of the proximal tibia after uncemented total knee arthroplasty. A prospective randomized study. Int Orthop. 2016;40(2):285-94.

116. Minoda Y, Kobayashi A, et al. Porous tantalum tibial component prevents periprosthetic loss of bone mineral density after total knee arthroplasty for five years-a matched cohort study. J Arthroplast. 2013;28(10):1760-4.

117. Jensen CL, Petersen MM, et al. Bone mineral density changes of the proximal tibia after revision total knee arthroplasty. A randomised study with the use of porous tantalum metaphyseal cones. Int Orthop. 2012;36(9):1857-63.

118. Faizan A, Bhowmik-Stoker M, et al. Development and verification of novel porous titanium metaphyseal cones for revision total knee arthroplasty. J Arthroplast. 2017;32(6):1946-53.

119. Family R, Solati-Hashjin M, et al. Surface modification for titanium implants by hydroxyapatite nanocomposite. Caspian J Intern Med. 2012;3(3):460-5.

120. Cook SD, Thomas KA, et al. Hydroxyapatite-coated for orthopaedic implant applications. Clin Orthop Relat Res. 1988;232:22543.

121. Bøe BG, Støen RØ, et al. Coating of titanium with hydroxyapatite leads to decreased bone formation. Bone Joint Res. 2012;1(6): 125-30.

122. Watters TS, Martin JR, et al. Porous-coated metaphyseal sleeves for severe femoral and tibial bone loss in revision TKA. J Arthroplast. 2017;S0883-5403(17):30536-3.

123. Dalury DF, Barrett WP. The use of metaphyseal sleeves in revision total knee arthroplasty. Knee. 2016;23(3):545-8.

124. Maier GS, Kolbow K, et al. The importance of bone mineral density in hip arthroplasty: results of a survey asking orthopaedic surgeons about their opinions and attitudes concerning osteoporosis and hip arthroplasty. Adv Orthop. 2016;2016:8079354.

125. Di Gregorio S, Del Rio L, et al. Comparison between different bone treatments on areal bone mineral density (aBMD) and bone microarchitectural texture as assessed by the trabecular bone score (TBS). Bone J. 2015;75:138-43.

126. Kanis JA. Diagnosis of osteoporosis and assessment of fracture risk. Lancet. 2002;359(9321):1929-36.

127. Ferket BS, Feldman Z, et al. Impact of total knee replacement practice: cost effectiveness analysis of data from the osteoarthritis initiative. Br Med J. 2017;356:j1131.

128. Skou ST, Roos EM, et al. A randomized controlled trial of total knee replacement. New J Med. 2015;373:1597-606.

129. Robertsson O, Dunbar M, et al. Patient satisfaction after knee arthroplasty: a report on 27,372 knees operated on between 1981 and 1995 in Sweden. Acta Orthop Scand. 2000;71(3):262-7. 